\title{
Communicative Textbooks: English Language Textbooks in Iranian Secondary School
}

\author{
Mahdi Dahmardeh (Warwick)
}

\begin{abstract}
English language teaching materials (textbooks) play an important role in many language classrooms, but recently there have been a lot of debates within the English language teaching profession based on the actual role that materials play in teaching English as a foreign language. Arguments have encompassed both the potential and the limitations of materials used for 'guiding' students through the learning processes and curriculum as well as the needs and preferences of teachers who are using the textbooks that are available. Other issues that have arisen in recent years include textbook design and practicality, methodological validity, the role of textbooks in innovation, the authenticity of materials in terms of their representation of language, communicative textbooks, and balance in presenting the language skills as well as cultural components.
\end{abstract}

The purpose of this article is to report the findings of a study carried out in 2006 into how Iranian textbooks could be made more communicative. The textbooks referred to are three English language textbooks, which are currently used in Iranian Secondary Schools. Although the work has been done within Iranian context, many suggestions could be applied to other foreign/second language situations.

I will start my discussion by presenting an overview about the English language teaching in Iran, before and after the revolution. This will be followed by presenting the findings of this research that would include the Iranian ELT curriculum, the questionnaire survey (author's and teachers' perspectives as well as their discomfort will be addressed) as well as introducing the English language coursebooks for secondary schools in Iran (topic, progression, structure of the lessons, types of exercises etc.). I will then present a discussion on findings of this research which would be a detailed exemplary criticism and suggestions for changes to make the materials communicative.

The findings of this explanatory case study revealed that there are many inconsistencies between the learners' needs, and the textbooks that are available for learning and teaching the English language though a few of them are reliable. The purpose of this research project is to recommend constructive changes, in order to make the textbooks more communicative as well as compatible with the students' and teachers' needs and expectations.

\section{$1 \quad$ An Overview}

The textbook factor is not only one of the few truly perennial issues in discussion of language teaching, it is also one of the few truly popular issues. The relation between textbooks and language teaching is not something which has only recently been commented on. It has cropped up in writings about language over many centuries. Probably the most important issue in this argument is to consider how textbooks should be designed in order to be the best. It is necessary to be cautious in using a word 'best' rather than 'perfect' because according to 
Grant (1987: 118) "the perfect textbook does not exist, but the best book available for you and your students certainly does" (cited in McGrath 2002: 41).

When it comes to teaching English the textbook issue would be considered as one of the most important topics in countries like Iran in which this language is considered as a foreign one. The English language is one of the compulsory subjects in the Iranian curriculum. Before the Iranian Revolution, in order to make the situation ideal, English native speakers were being employed to teach English to the students. After the Revolution (1979) due to circumstances, the system has changed thoroughly. In the Ministry of Education an organization has been established to design the textbooks for schools.

With respect to the textbooks, it needs to be explained that in Iran all the textbooks for the schools are produced by the Ministry of Education and no alternatives are available. These course books are taught in both private and public schools and all the teachers follow the same syllabus. A secondary school in Iran includes 4 years of studying and in each level there is one book for Teaching English as a Foreign Language (TEFL). English language teachers are supposed to cover one book during each educational year. As mentioned earlier, the main concern of this research is the 3 English course books which are used in 3 levels of the Iranian Secondary Schools. Every academic year is composed of two terms (each term includes nearly 12 weeks) and the English language is taught in both terms. In other words, every course book is divided into two equal portions and every section would be taught within a term. Moreover, book 1 includes nine lessons, book 2 has seven lessons and book 3 consists of six lessons and they all follow the same structure. Moreover, each lesson is composed of 8 main parts (New Words, Reading, Write It Down, Speak Out, Language Functions, Pronunciation Practice, Vocabulary Review, Vocabulary List). ${ }^{1}$

The study that is going to be reported here, will address a new area in Iranian English Language Teaching (ELT). This would explore the teachers' perspectives and their perceptions of students' needs by means of a questionnaire distributed among 20 Iranian English language teachers. These aspects were considered because of the importance of learners and teachers needs as well as their role in the Communicative Language Teaching ${ }^{2}$ (CLT) (Littlewood 1981). A further aim of this article is to find out about teachers and authors perspective about supplementary and authentic materials, which are provided as a support to the textbooks.

Iranian students have to study English for nearly seven years (3 years in Guidance school, 3 years in Secondary school and 1 year in Pre-University level), yet the education they receive neither enables the students to attain full competence in using the English language nor helps them to interact with confidence. Having considered the students' lack of success in communicating in English with colleagues in different parts of Iran and according to the questionnaire survey, the Iranian curriculum and the textbooks, bearing in mind current literature (i. e. Nunan 1999; McGrath 2002; Gower et al. 2005 etc.), it is concluded that some of the problems teachers and learners encounter can be traced to the textbooks. Moreover, it may be that there is a degree of ambivalence in the attitude of Iranian government towards English. The current political situation, in which the American president has spoken of Iran as an enemy nation, may not dispose the Iranian government to a particularly positive view of English. Such political issues may have an effect on the experience of students and teachers of ELT.

\footnotetext{
1 See Appendix 1 for the lesson contents.

2 According to Richards/Rodgers (2001: 155) "Communicative Language Teaching aims to (a) make communicative competence the goal of language teaching and (b) develop procedures for the teaching of the four language skills that acknowledge the interdependence of language and communication".
} 
Although, a lot of efforts have been made in order to find some literature or research that would best describe ELT in Iran or present some knowledge about the context, at the time of conducting this research nothing was available that could be relied on. Based on the literature (about CLT) that has been touched upon and the results of the questionnaires, this paper tries to present possible modifications and strategies that could be applied to make these textbooks communicative, bearing in mind lack of facilities as well as Iranian context. It also seeks to identify aims of the textbook authors along with a consideration of main objectives and coordination of the current curriculum within the textbooks.

\section{$2 \quad$ Findings}

The bulk of this study is based on the data that have been collected via both quantitative and qualitative approach. A questionnaire was administered to 20 Iranian secondary school teachers and one of the authors of the textbooks. The Iranian National Curriculum for ELT and the textbooks were examined qualitatively. Prior to discussing about the considered materials for the purpose of this research I would like to present a summary about Iranian educational system.

To clarify, schools in Iran are composed of three levels. The first level which is called the primary school includes five years of studying. The students start their school at this level when they are 6-7 years old. Following that there is a guidance school which is comprised of three years. Having finished the guidance school the students will be then qualified to enter into a secondary school (high school) which involves four years of studying. Basically, the students are supposed to study twelve years to be entitled to attend a national university entrance exam in order to attend a university condition to pass the test successfully. Moreover, the English language is a foreign language in Iran and students are officilay taught English from the first year of the guidance school.

\subsection{The Curriculum}

The Iranian national curriculum for teaching English runs to more than 150 pages in the Persian language. "Students' acquaintance with other cultures" and "using the English language for training experts up to high levels" have been claimed as the two main goals of the curriculum (Sarab 2006).

Teaching four language skills has also been emphasised as one of the main aims of the national curriculum. However, careful analysis of the curriculum document suggests that its main concern is about reading comprehension and grammar. It is the case because each skill is defined in the framework of reading. Furthermore, the bulk of the document is devoted to a presentation of reading strategies and how to teach this skill as well as teaching grammar.

\subsection{The Questionnaire Survey}

Due to research aims it was determined that there had to be two groups of participants in the project. The first group composed of English language teachers who were teaching in Iranian secondary schools and the second group involved the textbook designers. Thus, two types of questionnaire were administered; one for the teachers and the other for the authors of the textbooks. ${ }^{3}$ The teacher participants were chosen from southern province in Iran called Sistan and Baluchistan. About 50 questionnaires were distributed among English language teachers in secondary schools (Public Schools) and 20 responses were collected. Basically, there were

\footnotetext{
${ }^{3}$ See Appendix 2 for the questionnaires.
} 
20 teacher participants and one author who agreed to participate in this project. ${ }^{4}$ Both questionnaires were distributed in 2006 and the results are going to be discussed hereafter.

\subsubsection{Responses Given by the Author}

The author of the textbooks believed that helping learners to acquire basic components in general English in order to function in tertiary education was the main goal considered while designing the textbooks. He explianed the available time for teaching the English language in the curriculum, the teacher's qualifications and the system for assessment as well as teaching facilities were the main constraints that they had while designing the textbooks.

Concerning the language skills (listening, reading, writing and speaking), he explained that reading was emphasised most because it was assumed that this skill is required more in tertiary education. Interestingly, he indicated that these textbooks are not communicative at all and the reason for this explained by him as the structural approach that was adopted by the committee of writers. Also, it was emphasised that the current textbooks are not designed based on any curriculum at all and the national curriculum has been recently developed.

Having asked about authentic and supplementary materials, the author believed that the teachers must be encouraged to apply them in their teaching but these materials currently are mainly test books (composed of huge number of tests and questions to make students ready for exams). It is the case because, according to him, the teachers are mainly concerned with preparing the students for the exams. Therefore, the only available materials besides textbooks are books which are designed to prepare students for tests and exams. Finally, the author identified flaws and disadvantages of the current course books as,

a) Lack of coherence

b) A narrow curriculum

c) Form-based exercises

d) Lack of flexibility

\subsubsection{Responses Given by the teacher participants}

Most of teachers who participated in the survey identified the issues below as their main concerns during teaching,

a) Students achieve some skills at least in reading comprehension.

b) Preparing students for the final exam and help them pass in the end.

Concerning the supplementary materials, $50 \%$ of the teacher participants claimed that these materials are not available to them. Even the rest of the teachers who claimed that such materials are available were not happy with the content of supplementary materials and described them as 'poor quality'. Furthermore with respect to authentic materials, only $15 \%$ of the teachers claimed that they use authentic materials and the rest of them argued that because of time limit they were not using such materials.

Having said that, like what the authors stated, the teachers also described the current textbooks as not communicative..$^{5}$

\footnotetext{
${ }^{4}$ Although a lot of efforts have been made to get access to the textbook authors, only one of them was available and agreed to cooperate. Luckily he is not only a textbook writer but also is a person who has directly involved in designing the Iranian Curriculum.

${ }^{5}$ It is necessary to clarify that in the questionnaires we did not directly ask whether the teachers think that the textbooks are communicative or not. Because, it was thought that they may not be familiar with the term 'communicative', therefore, we decided to ask some questions e.g. question 4 of the questionnaire (based on the communicative criteria) that we could infer whether they think the course books are communicative or not.
} 
In response to a question about the main purpose of the textbooks and what aspect(s) of language has/have been most emphasised, the teachers identified issues below as the main goals:

a) The main objective is to concentrate on reading comprehension.

b) The objective of the textbooks is to teach and introduce all the learning skills and mainly reading comprehension and speaking.

c) To teach students how to apply words in sentences correctly.

d) To teach some phonetic symbols and pronunciation.

e) The students can benefit from some vocabularies and some grammatical structures in the textbooks.

Also, the chart below is to show the above claims in a numerical framework.

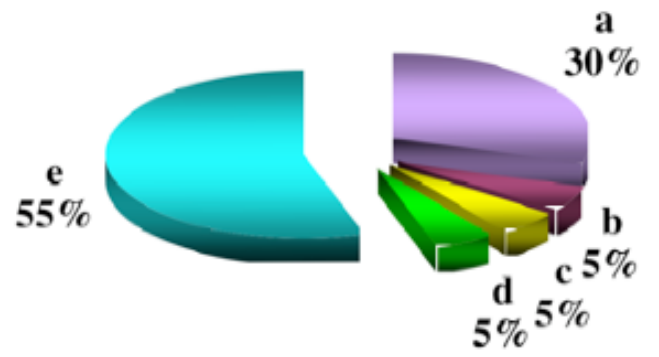

The aims of the textbooks (Teachers' points of view)

Having asked about their general attitude towards the textbooks, 17 people (out of 20) argued that they were not happy at all and the rest of them gave a neutral answer. This suggests that the teachers were not really pleased with these materials.

\section{Discussions and Implications}

The way that the language skills are presented in the textbooks is the first issue that is going to be discussed. According to the teacher participants, the presentation of the skills in these course books seems naive. Each lesson includes a variety of sections such as New Vocabulary, Reading, Speak Out, etc., while each section tries to present only one or two aspects of language. One of the key principles of communicative pedagogy is to teach skills in an integrated manner (Littlewood 1981); and that is because language learning is not learning the language skills solely and separately from each other. On the contrary, it is a combination of all the four skills together. Moreover according to the advoctaes of CLT, language teaching is something more complicated which deals with tasks and activities that are to prepare the learners to overcome the problems that they encounter in real life. Therefore, in order to achieve a degree of communicative ability, it is necessary to expose learners to conditions in which the integration of language skills and the development of cognitive style ${ }^{6}$ occur. Consequently, this would help them to imagine that they are in real situations so they would be able to cope with their difficulties. For example, based on the work of Gower et al. (2005) the discussion below might be a possible strategy.

\footnotetext{
6 Cognitive style: the particular way in which a learner tries to learn something. In second or foreign language learning, different learners may prefer different solutions to learning problems. For example, some may want explanations for grammatical rules; others may not need explanations. Some may feel writing down words or sentences helps them to remember them. Others may find they remember things better if they are associated with pictures. These are called differences of cognitive style (Richards/Schmidt, 2002: 58).
} 
Let us assume that a teacher is planning to present a newspaper article to his/her students. Firstly, he/she starts the session by talking about a topic and probably showing students some relevant photos in order to find out about what the learner may know about the topic. This may be followed by watching or listening to a report that was recorded about the topic. Then, the learners might be asked to talk about the subject or they can directly start reading through the article and try to understand the text. Finally, the learners can be told to write a letter to an editor of a newspaper leaving their comments about an article. From what has been said it can be realised that all the language skills could be presented not only in an integrated manner but also in an authentic way.

Furthermore, bearing in mind the principles of CLT as well as comments made by the teacher participants, the next section is to suggest some teaching strategies that could be applied in order to make the textbooks communicative. The sections below are different parts of each lesson that will be examined and followed by some suggestions.

\subsection{Teaching New Vocabularies}

In this section of the textbooks new words are presented out of a plausible context as isolated sentences. Let us take an example from one of the textbooks: "Some people never forget what they learn. They have a good memory." At this point, the word memory, as underlined, is the new vocabulary which students are supposed to learn.

Advocates of CLT suggest that introducing new vocabularies needs to be practised within a known context. By embedding new words in a plausible context, words are more likely to be recognised, more likely to be related to existing knowledge and are more easily accessed in memory. The best way of teaching vocabularies is by presenting them within a context along with appropriate illustrations. This can make the process of learning more authentic and also by the help of context; the learners could guess meaning of new words. Thus, it may help to embed in memory.

\subsection{Reading Comprehension}

This section is mainly composed of a substantial passage which is followed by some questions about the text. These questions are basically true/false items, multiple choice items as well as open ended or short answer questions.

Bearing in mind principles of CLT, teaching reading can be done by presenting a new, interesting and authentic text. Preferably, it may be something related to learners' knowledge that would make it more understandable and interesting to them. The text is supposed to provide learners with an opportunity to feel real life. Moreover, interesting texts can motivate learners. Having said that, it needs to borne in mind that the length of passages must be chosen properly since by choosing long passages there is always a danger of making students tired.

Krashen (2004) introduced the term Free Voluntary Reading (FVR) as the foundation for reading proficiency. He has suggested that it is very important to encourage the learners to read as much as possible, but at the same time it should be taken into consideration that the learners must be free to choose their own texts and at the same time interesting books should be provided by the teachers.

\subsection{Speak Out And Write It Down}

Although the word write occurs within the title, according to the teacher pariticipants as well as the analysis of the textbooks, this section is mainly concerned with speaking as well as introducing some grammatical structures. This section presents a grammatical structure 
followed by some examples to exemplify how to apply it within a sentence. So, the teacher practically reads them aloud and students are then supposed to repeat them. For instance,

\section{Structure 1: Noun Clauses \\ I don't know who lives in that apartment. \\ We don't know what will happen next.}

Furthermore, there are some substitution drills for the students to practise. Finally, some questions are presented and the learners are asked to answer them based on what they have already learned in this section. Moreoever, there will be another grammatical structure which would be presented in the same order like the preceding one. Usually two grammatical points are taught in each lesson deductively.

The first obvious problem of this section which contradicts the basic principle of CLT is its emphasis on drilling exercises. Nunan (1999: 76) clarified that drills cannot equip the learners to communicate and the learners should be provided with opportunities to use the language creatively. Furthermore, according to Harmer (1991: 59),

A more effective - and less frightening - way of presenting form is to let the students see/or hear the new language, drawing their attention in a number of different ways to the grammatical elements of which it is made.

So, one of the suggestions in order to teach grammatical structures might be introducing them by practising authentic conversations. For instance, in order to practise past tense, teachers might ask two students to talk about activities that they have done previously, after exposing them to an authentic conversation between two friends who talk about the activities that they did before. It is necessary to keep it in mind that the learners should not be required to imitate the same conversation. The advantage of this type of practice is that the students are free to choose meaningful answers which would also make the activity authentic and more interesting.

Meanwhile, the introduced grammatical item might be picked up by the learners automatically. Also, in order to make sure about students' thorough understanding of the new structures, the teacher can simply try to assess students' acquired knowledge by modifying the exercise and practicing some other types of exercise which would still include the same grammatical structure.

\subsection{Language Function}

This part is slightly similar to the Speak Out section and is to practise oral skills by presenting some speaking exercises. The only difference between this part and the previous one (Speak Out) is that it mostly deals with daily conversations rather than focusing on a specific grammatical structure. The way these points are presented to the learners is identical to its earlier counterpart. For instance, a conversation about a time table might be presented at first and then the pupils would be asked to practise the same dialogue by repetition. To sum up, the majority of teacher participants argued that all the activities are sort of drilling exercises.

In order to achieve a degree of communicative ability, it is necessary to provide some situations where the language skills and the development of cognitive style would be integrated and the learners could imagine that they are in real situations and it is the time when they are supposed to cope with their difficulties, for example. The context also has an important role in the communication and the learners should be able to use the skills effectively based on the nature of the interaction in the variety of combinations (Cunningsworth, 1984:43).

Thus, as discussed earlier, it would be quite unlikely that someone can communicate effectively in a target context only by practising some drilling exercise. What the advocates of 
CLT suggest is to view communication as "bridging an information gap" (Johnson: 1982: 250). One way to do this is by asking the learners to tell stories about themselves and to talk about things that are so far unknown to their classmates. It makes the communication happen since it would motivate others to listen carefully in order to understand; consequently, an interaction among people will be resulted. That is the case, because firstly, pupils would want to know more about the topic and secondly, in order to fulfil the existed gap in their knowledge they need to ask which would make the communication happen.

\subsection{Pronunciation Practice}

At this stage, three different sounds i. e. /s/, /Iz/, /z/ are introduced. These sounds and how they pronounced are explained by the teacher and then the learners would be asked to categorise some vocabularies (a list is provided) according to the relevant sounds that were introduced earlier by the teacher.

Teaching pronunciation at this stage could be a very complicated task that needs a lot of consideration. Bearing in mind what Harmer (1991: 22) suggested, I would expose the learners to near native English speakers or preferably native speakers. This could be done by listening or watching some interactions or conversations between two English native speakers. The advantage of this would be to hear the correct pronunciation of every single word, including word stress and sentence stress.

\subsection{Teaching Listening And Writing}

Having considered the textbooks as well as the comments made by the participants, there was no sign of presenting or even teaching these two language skills (Listening \& Writing). It is obvious that one of the main elements of CLT is missing, integration and presenting all the four language skills. One of the fundamental principles in teaching English and in general any other language, is keeping a balance in presenting a variety of language skills (Gower et al., 2005).

Listening comprehension could be taught through different techniques. Bearing in mind the situation and facilities that are available to the Iranian teachers I would suggest a strategy to combine reading and listening together. Since each lesson includes a passage for reading comprehension practice, then it could be used for listening comprehension as well. In order to do so, passages of the textbooks could be read and taped by English native speakers. Having provided teachers with such audio tapes, they could simply play them before the class prior to starting the reading exercise. Simultaneously, the learners would be asked to listen and try to find out about the topic and subject of the text as much as they could. This practice could be followed by some other activities like interactions or discussions between the students about the topic.

As for the writing skill, Harmer (1991) suggested the exercises below which might be useful:

a) Relaying instructions

b) Writing reports

c) Co-operative writing

d) Exchange letters

e) Writing journals

These ideas could be expanded by presenting some authentic texts like letters or compositions to the students. Later on, if required, a variety of writing styles e.g. descriptive or narrative might be explained to the learners. 


\subsection{Teaching Culture}

There is a lot of discussion among scholars e.g., Chastain (1988), McGrath (2002) and many others who strongly support the idea of teaching the culture of a foreign language that is taught. However, the textbooks did not include anything about the culture of English speaking countries. For instance, all the names or situations that are presented in the textbooks are Iranian. This may be a political decision but, if so, it is a major barrier to communicative language teaching.

It is strongly recommended to include the culture of English speaking countries, e.g. Great Britain, Australia, or any other country where English is spoken as the or one of the first languages. Such a problem, not including the foreign language culture, is very likely to happen in situations like Iran where the native culture is completely different from the target one. There might be some people, who would say that some of these aspects could be covered by media including satellite programmes, but access to satellite TVs for Iranians is prohibited and it has been forbidden by the Iranian governments.

\section{Concluding Remarks}

This research is a preliminary work investigating how to make the Iranian secondary school's English language textbooks communicative. Having considered the collected data from a variety of sources (Textbooks analysis as well as comments made by the respondents), it has been concluded that,

1. Iranian students have to study English as a foreign language for nearly seven years in the schools ( 3 years in Guidance school, 3 years in Secondary school and 1 year in PreUniversity level), yet the education they receive neither enables the students to attain full competence in using the English language nor helps them to interact with confidence.

2. English language classes have become nearly one of the boring classes for both teacher and students.

3. It is surprising then to find that there is no evidence of non-Iranian culture in the textbooks.

To sum up, these textbooks can not meet the learners' and the teachers' needs within the Iranian educational system and it is a bit strange that they still emphasise structural methods and ignore the communicative role of the language. This paper tried to present some possible strategies, based on the literature that was being reviewd and what the teacher participants expected, which hopefully can make a great change to the textbooks in order to make them communicative. English language teaching will definitely generate more and more arguments in Iran and the issue of textbooks in particular. In terms of making the textbooks communicative, this study is just a trial. Future research in this area may place the emphasis on how these findings could affect the real classroom situation or how to design a communicative curriculum for teaching English within the Iranian Educational System.

\section{References}

Birjandi, Parviz/Nourozi, Mahdi/Mahmoodi, Gholam Hussain (2005): English Book 2. Tehran.

Birjandi, Parviz/Nourozi, Mahdi/Mahmoodi, Gholam Hussain (2005): English Book 3. Tehran.

Birjandi, Parviz/Soheili, Abol Ghasem/Nourozi, Mahdi/Mahmoodi, Gholam Hussain (2005): English Book 1. Tehran.

Chastain, Kenneth (1988): Developing second-language skills: Theory and practice. $3^{\text {rd }}$ ed. San Diego (CA) etc.

Cunningsworth, Alan (1984): Evaluating and selecting EFL teaching materials. London. 
Dubin, Fraida/Olshtain, Elite (1986): Course design: Developing programs and materials for language learning. Cambridge.

Gower, Roger/Phillips, Diane/Walters, Steve (2005): Teaching practice: A handbook for teachers in training. Oxford.

Harmer, Jeremy (1991):The practice of English language teaching. London.

Johnson, Keith (1982): Communicative syllabus design and methodology. Oxford/New York.

Krashen, Stephen (2004): The power of reading: Insights from the research. Portsmouth (NH).

Littlewood, William (1981): Communicative language teaching. Cambridge.

McGrath, Ian (2002): Materials evaluation and design for language teaching. Edinburgh.

Nunan, David (1999): Second language learning and teaching. Boston.

Richards, Jack/Rodgers, Theodore (2001): Approaches and Methods in Language Teaching. $2^{\text {nd }}$ edition. Cambridge.

Richards, Jack/Schmidt, Richard (2002): Longman dictionary of language teaching and applied linguistics. $3^{\text {rd }}$, revised edition. London.

Sarab, Mohammad Reza Anani (2006): The Iranian curriculum for designing secondary school's English language textbooks. Tehran.

\section{Appendix 1}

What each unit (lesson) includes:

Part A (New Words)

Introducing new words to the students and making them familiar with new vocabularies. To do so, the teachers are not supposed to use the Persian language. The teacher teaches the meaning of vocabularies to the students by using a variety of educational techniques which are used in teaching words (showing objects, gesture, pictures, presenting simple definitions, synonyms and antonyms). The teacher should also provide an opportunity for the students to practice the English language in an interaction by using taught sentences in this part. Furthermore, in this part a function of vocabularies and a way of using them with sentences are being considered.

This section includes between 6 and 8 parts. In each part one or two sentences are presented. Each sentence introduces one or two new vocabularies. These are followed by one or two questions about the sentences. The questions are also followed by an illustration which is about the subject of the presented sentences.

\section{Part $B$ and $C$ (Reading)}

The purpose is reading comprehension. The text should not be translated for the students. The purpose is not teaching 'translation'. The aim is to understand an English passage by the pupils without using their mother tongue. The teacher should not explain the grammatical rules of the sentences in the text for the students.

Basically, in each lesson a text which is about a historical event or an invention is presented. This is titled as 'Reading'. The reading is followed by 'Comprehension' section which includes 'True or False', 'Multiple Choice' and 'Short Answer Questions' which are questions about the text. This part also includes a section which asks the students to answer some questions about the text orally. It mainly tries to find out students' understanding of the text. The new words presented in previous section are also repeated in the reading section.

\section{Part D and E (Write It Down, Speak Out)}

In these parts grammatical rules are presented. Activities like repetition, substitution, transformation and production are applied. It should be borne in mind that although it is 
claimed that the grammatical rule is not the aim itself, and it is a tool for perfect writing, reading and speaking but these parts are mainly concerned with teaching the English grammar.

Each lesson represents 1 or 2 grammatical points. These are presented deductively in a way that the structure is presented in a first instance and then it is followed by examples and practice. Having presented the grammatical points the students are supposed to practice them according to the presented models. The exercises are mainly concerned with: substitution, making new sentences (follow a model), answering questions and making new sentences using words in brackets. The preceding activities should be done orally.

In the 'Write It Down' section the students are supposed to produce and write sentences about themselves based on the grammatical points which are taught in the lesson. In general all the practices in these sections are about: repetition, substitution, transformation and production.

\section{Part F (Language Functions)}

Sentence elements in this part are not discussed from grammatical point of view. There are some points in some sentences that the students have not been taught yet. The students are not asked to memorize the sentences parrot like but they should learn them naturally by practicing and role playing. Finally, the students are supposed to talk and interact with each other based on their roles in different situations.

In this part some dialogues about different topics are presented which the students are supposed to practice them in pairs as a role play.

\section{Part G (Pronunciation Practice)}

The purpose is to make students familiar with correct pronunciation of the English alphabets and vocabularies. The teaching is performed by repetitions, practice and maybe by playing interesting games.

Each lesson presents one or two phonetic symbols. First of all, the sound is presented in the square brackets and then it follows by some words which have the same sound in themselves.

In the second part the students should distinguish between other sounds and the one which is presented in the lesson. Here the teacher has the main role because he/she should teach correct pronunciation of the word and the students should imitate him/her.

\section{Part H (Vocabulary Review)}

This part is a practice review for the vocabularies that are taught in this lesson to the students.

\section{Part I (Vocabulary List)}

Here a list of the new vocabulary that has been introduced to the students in the lesson is presented. 
A Sample Lesson (Grade Three, Secondary School)

\section{LESSON TWO}

\section{A. NEW WORDS}

a. He is working hard. He wants to go to university.

He plans to study physics. I think this is a good end

b. He loves to help people. Helping people is his end in life.

c. I don't like your way of life. You're always talking about money. It is an end for you

2.

a. All parents should send their children to school.

For many parents, this is an important end. They think that they should educate their children

b. The government spends a lot of money on educating children.

a. He spoke English so well that I never realized he was German.

b. The police realized that the man was lying.

a. You should not hurt little children. You should be ashamed of what you do.

b. John didn't get a good mark in his history test. He is ashamed of showing that to his father.

c. Some students do silly things in the classroom. They are never ashamed of what they do.

\section{THE VALUE OF EDUCATION}

\section{B. READING}

1 Education is not an end, but a means to an end. In other words, we do not educate children only for the purpose of educating them; our purpose is to fit them for life. As soon as we realize this fact, we will understand that it is very important to choose a system of education which will really prepare children for life. It is not enough just to choose the first system of education one finds; or to continue with one's old system of education without examining it to see whether it is in fact suitable or not:

2 In many modern countries it has for some time been fashionable to think that by free education for all - whether rich or poor, clever or stupid - one can solve all the problems of society and build a perfect nation. But we can already see that free education for all is not enough. We find in such countries a far larger number of people with university degrees than there are jobs for them to fill Because of " de their degrees,

3 But we have to understand that any society needs different services and all jobs are important and useful. We need farmers to produce food. We need teachers to educate people. Weneed doctors to cure the sick. We need people to clean our streets and take the rubbish away from our houses.

4 However, we can say that all of us must be educated. This education should prepare the person for the job he can do best. We know that all jobs are useful, and no one should be ashamed of one's work.

free education for all cannot solve all the problems of a nation 4. According to the passage ......... a. education is more important in some countries b. education is not needed by farmers

c. without education cities will not be clean

d. everybody needs some kind of education

1. Answer the following questions.

2. Is education an end for you?

3. Can education prepare children for life?

4. Are all systems of education suitable?

5. Is education free in all countries?

6. Can we live without education?

7. Should all people have education?

8. Is it easy (or possible) to educate everybody?

II. True/False

-1. We should realize that education is not an end by itself.

-2. The final goal of education is to help people to get higher university degrees.

- 3. Free education for all can solve all the problems of society.

- 4. Those who clean the streets have also a great role in our society.

- 5. Doctors and nurses are the only group of people who help us have a healthy life.

III. Complete these sentences. Use $a, b, c$, or $d$.

1. The only purpose of education is .............

a. to educate people

b. to prepare children for life.

c. to prepare children for examinations

d. more than an end

2. We should

a. choose any system of education

b. test many systems and choose the best on

c. continue our own system of education

d. not examine other systems at al

3. From the passage we understand that

a. free education is the best way to become a successful nation

b. free education for all is not very much suitable

c. educated people are ready to do all kinds of work 


\section{SPEAK OUT}

\author{
Structure 1: be + adjective + for + object + infinitive \\ Speaking 1 \\ Usten and repeat. \\ It is easy for me to learn English. \\ It is necessary for you to speak English correctly. \\ It was important for us to finish the book. \\ It wasn't difficult for him to climb the tree. \\ Speaking 2 \\ Substitution Drills \\ Substitute the words in the pattern sentences. \\ A) It is necessary for him to read the sentences correctly. \\ 1. easy \\ 2. possibie \\ B) It isn't easy for me to answer these questions. \\ 1. us \\ 2. her \\ C) It was difficult for me to walk. \\ 1. understand the lesso \\ 2. run fast \\ 3. repair the bicycle
}

I dislike washing dirty dishes.

He never stops talking.

We're tired of sitting here. (Preposition + Gerund)

They're interested in working here.

We thanked him for answering our questions.

She insisted on going there.

Speaking 2

\section{Substitution Drills}

Substitute the words in the paftern sentences. Make changes if necessary.

A) Working for a long time made him tired. 1. Studying/her

2. Practicing/me

3. Teaching/John

4. Speaking/ him

B) He was tired of living in this apartment.

1. was interested in / read / English stories

2. insisted on / buy / the shoes

3. was thinking about/ repair/ the house

4. will keep on / learn/English

Speaking 3

Make questions with the words given. Look at the pictures and give proper answers.

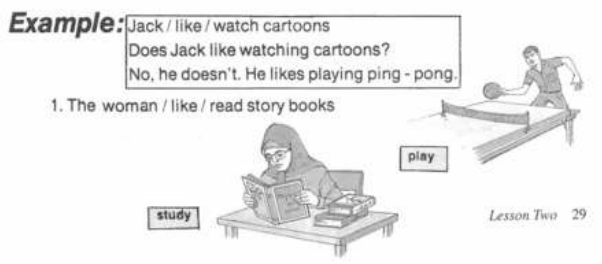

Speaking 3

Use the following words to make sentences.

Example: hard / Ali / answer / the questions It is hard for Ali to answer the questions.

1. difficult / the students / do/ so much homework

2. necessary / her / put on / a coat

3. easy / them / find / a good restaurant

4. important / young men / wear / good clothes

5. impossible / the women / find / the address

Speaking 4

Answer these questions. Use the words in parentheses.

Example: Can a little boy drive a car? (impossibie) No, it is impossible for a little boy to drive a car.

Can you read a book in a dark room? (impossible)

2. Can your English teacher speak English? (easy)

3. Should students ask questions in the classroom? (necessary)

4. Should you do your homework carefully? (necessary)

5. Can students get good marks if they study hard? (easy)

Structure 2: The Gerund (verb + ing)

Speaking 1

Listen and repeat.

Learning English is easy.

Driving carelessly is dangerous.

Smoking in this room is forbidden.

Playing ping - pong for two hours made him tired.

llike swimming

(Verb + Gerund)

She enjoys walking in the park.

28 Lesson Two

2. Maryam / enjoy/make dresses

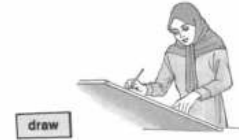

3. Mr white / dislike / eat cake
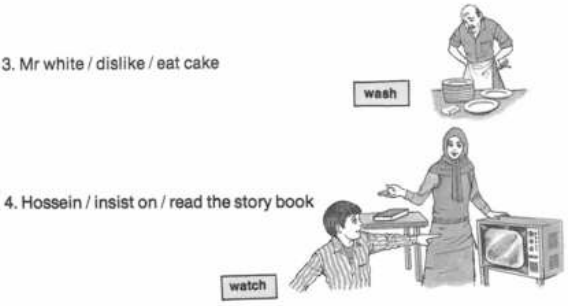

Speaking 4

Look at the pictures and answer the questions.

Example: What has made Ali tired?

Playing football has made him tired.

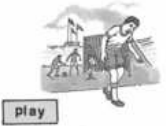

What has made Maryam tired?

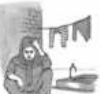

wash

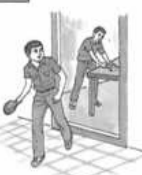


3. What made Hadi happy last summer?

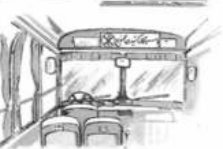

\section{E. WRITE IT DOWN}

Writing 1

Answer these questions.

Example: Is it safe to swim in this river?

No, swimming in this river isn't safe.

1. Is it difficult to learn English?

2. Is it necessary to stand in line?

Yes,

3. Is it important to be on time?

4. Is it easy to find a job here?

5. Is it dangerous to drive on this road?

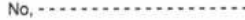

Writing 2

Write some sentences about yourself. Use the words "like, enjoy,

prefer, tired, interested."

\section{To the teacher:}

Structure 1: be + adj $+($ for + object $)+$ infinitive

\section{Compare:}

A. It is necessary to come early to class.

B. It is necessary for you to come early to clas.

A. It is hard to speak Japanese.

B. It is hard for Ali / him to speak Japanese.

Note: In each pair, sentence A talks about the action generally while sentence $B$ talks about the person who is involved in the action.
Writing 3

Makequestions with the given words. Then answer the questions.

Example: possible/you/readin a darkroom

a) Is it possible for you to read in a dark room?

No, it is impossible for me to read in a dark room.

difficult/a at man/ run fas

b) Is it difficult for a fat man to run fast?

Yes, it is difficult for a fat man to run fast.

1. easy / a blind person / walk in the street

2. easy/a taxi driver/drive a car

3. difficult/your English teacher/speak English

4. possible / a cat / climb a tree

5. difficult/ a good student/ get good marks

6. possible/ an elephant/go faster than a horse

Writing 4

Write five sentences like the above about yourself and the people you know.

\section{To the teacher:}

Structure 2: The gerund (verb + ing)

\begin{tabular}{|c|c|}
\hline Compare: & $\begin{array}{l}\text { A. It is easy to learn English. } \\
\text { B. Learning English is easy. (gerund + verb) } \\
\text { S. } \\
\text { A. l like to swim. } \\
\text { B. I like swimming. (verb + gerund) } \\
\text { A. I'm tired. } \\
\text { B. I'm tired of sitting here. (preposition + gerund) } \\
\text { O. of prep. }\end{array}$ \\
\hline \multicolumn{2}{|l|}{ Note: } \\
\hline \multicolumn{2}{|c|}{$\begin{array}{l}\text { 1. The gerund functions as a noun in the sentence. So it can be the } \\
\text { subject, object or object of preposition. } \\
\text { 2. The gerund like a verb can have an object and an adverb phrase. }\end{array}$} \\
\hline Example: & $\begin{array}{l}\text { Learning is easy. } \\
\text { Learning English is easy. } \\
\text { Learning English at school is easy. }\end{array}$ \\
\hline \multicolumn{2}{|c|}{$\begin{array}{l}\text { 3. Some verbs which can have gerund as object are: } \\
\text { avoid, enjoy, finish, imagine, keep, mind, miss, go on, dislike, risk, } \\
\text { stop, etc. }\end{array}$} \\
\hline
\end{tabular}




\section{F. LANGUAGE FUNCTION}

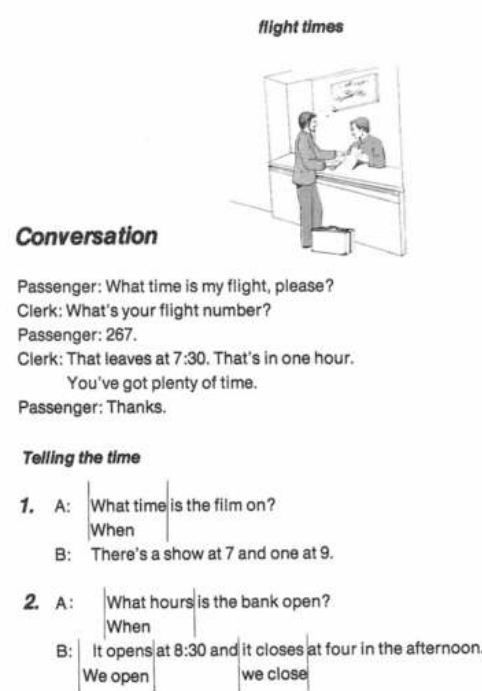

Now practice with a friend.

\section{G. PRONUNCIATION PRACTICE}

Stress means loudness. In English some syllables are pronounced $A$ A never happy mother$$
\text { In the above words the first syllable is louder. This means that it is }
$$
pronounced with more force.

Now listen to the following words. In these words the second syllable
is louder.
B
myself
above
ago
before
Now listen to your teacher as he reads the following words aloud. You
should identify the words which have a louder first syllable.
$\begin{aligned} & \text { after } \\ & \text { city } \\ & \begin{array}{ll}\text { little } \\ \text { added } & \text { enough }\end{array} \\ & \text { Can you add four more words to the above list? }\end{aligned}$

\section{H. VOCABULARY DRILL}

We add - ly to adjectives to change them into adverbs.

Example: bright + ly $=$ brightly

Use the following adjectives or their adverb forms in the sentences below. Make any necessary changes in spelling.

slow, final, real, honest, rapid, easy

1. Do you -.......... think you'll be able to pass your driving test?

2. Banks try to employ ......... people.

3. Preparing a dictionary is not as ......... as it may seem

4. My wateh is tive minutes

5. Itried to answer all your questions.........

6. After a long discussion they .......... decided not to sell their car

7. He gave a (n) ........... answer to my question.

8.1 can .......... finish reading this book today.

\section{VOCABULARY}

\begin{tabular}{|c|c|c|c|}
\hline as soon as* & fact* & in other words" & refuse ${ }^{*}$ \\
\hline ashamed of ${ }^{*}$ & fashionable* & insist on & role* \\
\hline (be) on time & fill: & $\mathrm{lie}^{*}(\mathrm{v})$ & rubbish" \\
\hline blind & final $^{*}$ & means ${ }^{\circ}$ & service \\
\hline clerk & fit' & modern ${ }^{*}$ & show (n) \\
\hline dangerous & flight & nation: & silly" \\
\hline degree* & forbid & passenger & society" \\
\hline discussion & free ${ }^{*}$ & perfect" (adj) & stupid* \\
\hline dislike & goal* & possible & take away from ${ }^{*}$ \\
\hline driving test & government" & prepare: & useful" \\
\hline educate* & honest & produce ${ }^{*}$ & What time is the film on? \\
\hline end $(n)$ & however & rapidly & value \\
\hline examine: & in fact & realize & whether \\
\hline
\end{tabular}




\section{Appendix 2}

Questionnaires for the group of teachers.

(In order to save some room, the space between questions have been removed) Questions were presented in both Persian and English language.

We would like to know about your experience of using the English Language Textbooks which are currently used in Iranian Secondary Schools (High Schools).

You may use Persian or English in order to fill out the questionnaire.

What are your aims and your final goals which you would like to achieve at the end of educational year?

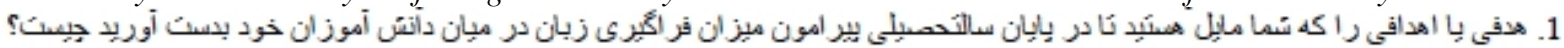

Is there any supplementary materials (like cassettes, books, etc. which are specifically produced for using accompanying with textbooks) available to you? If yes, do you use them?

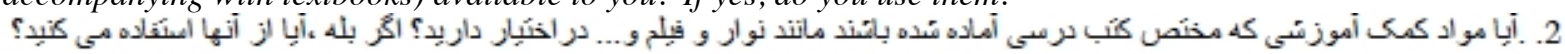

Do you use authentic materials (like story books, newspaper, etc.)?

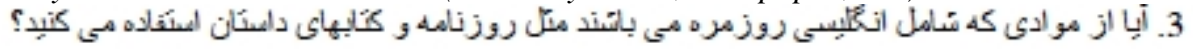

Having studied English as a foreign language for four years in the Secondary School (High School), do you think it is possible for the students to speak English up to an intermediate level? For example, Can they perform the following activities:

Taking a taxi in Britain

Doing a simple greeting

Reserving a room in a hotel in Britain

If not, why?

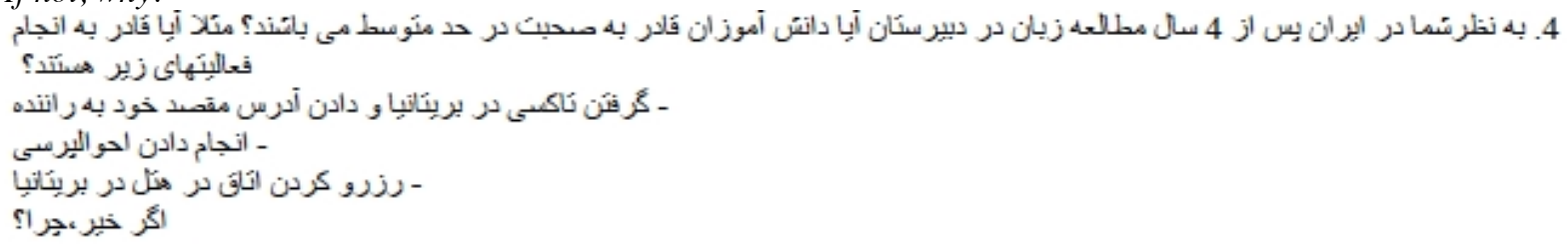

If you think after studying the current textbooks the students can not perform the preceding activities, how you would change the textbooks to make them suitable for such purposes?

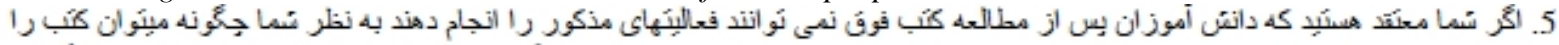

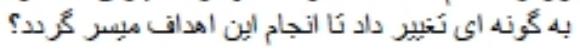

In your opinion, what is the main purpose of the textbooks and what aspect(s) of language has/have been more emphasised? Do you think it is the same as what is has been claimed?

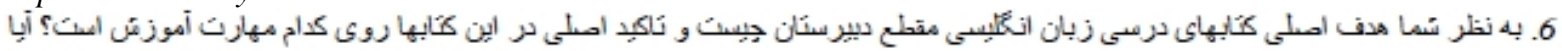

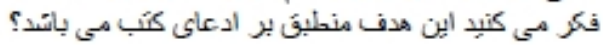

What is/are the main problem(s) with these textbooks (If there is any)?

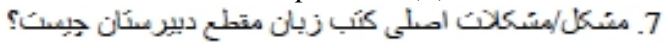

In general, are you happy with the current English Language textbooks or not? Would you please briefly explain your answer?

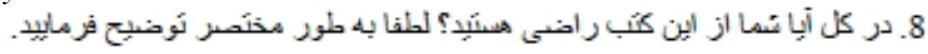


If you want to grade the current English Language textbooks between 1 and 5 what mark will you give them?

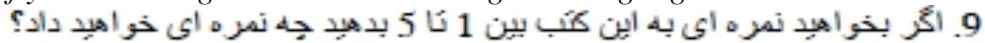

\begin{tabular}{|c|c|c|c|c|}
\hline Awful & Poor & Not Bad & Good & Excellent \\
\hline 1 & 2 & 3 & 4 & 5 \\
\hline
\end{tabular}

Questionnaires For The Author's Group (In order to save some room, the space between questions have been removed).

We would like to know about your experience in designing the English Language Textbooks which are currently used in Iranian Secondary Schools (High Schools).

You may use Persian or English in order to fill out the questionnaire.

When you were designed the textbooks what was/were your aim(s)?

What constraints did (do) you have in designing the textbooks?

In designing the textbooks what aspect(s) of language (Listening, Writing, Reading and Speaking) have/has been more emphasised? Why?

Do you think the current textbooks are communicative? If not, how you can make them more communicative?

As a person who is directly involved with designing the textbooks, why you did not include more communicative materials?

Do you advice teachers to use authentic materials (like story books, newspaper, etc.) and supplementary materials (if available) in the class? Please briefly explain.

In your opinion, to what extent is the content of the textbooks determined by the national syllabus?

Do you think there is any fault or shortcoming in the current textbooks? If yes, please explain it briefly. 